\title{
Contribuição à caracterização nanoestrutural de pastas de cimento por meio da técnica de Microscopia de Força Atômica
}

\author{
Contribution to nanostructural characterization \\ of cement pastes by the technique of \\ Atomic Force Microscopy
}

Oswaldo Cascudo ${ }^{1}$, José Henrique A. Fernandes ${ }^{2}$, Tatiane Oliveira dos Santos ${ }^{3}$, Helena Carasek ${ }^{4}$

\begin{abstract}
1,2,4 Laboratório de Inovação Tecnológica em Construção Civil - LABITECC, Programa de Pós-Graduação em Geotecnia, Estruturas e Construção Civil - PPG-GECON, Escola de Eng. Civil e Ambiental - EECA, Universidade Federal de Goiás - UFG. CEP: 74.605-220. Pça. Universitária, s/n, Câmpus Colemar Natal e Silva, Setor Leste Universitário, Goiânia - GO.

e-mail: ocascudo@gmail.com, josehenrique1@yahoo.com.br, hcarasek@gmail.com

${ }^{3}$ Laboratório Multiusuário de Microscopia de Alta Resolução - LABMIC, Instituto de Física - IF, Universidade Federal de Goiás - UFG. CEP: 74.690-900. Instituto de Física, Av. Esperança, s/n, Câmpus Samambaia, Goiânia - GO. e-mail: tatiane_oliveira@ufg.br
\end{abstract}

\section{RESUMO}

Tem sido creditado à nanociência um destacado papel de prover pleno entendimento sobre o comportamento macroscópico dos materiais, por ser esse campo da ciência capaz de realizar estudos e perceber, com distinção, propriedades ou fenômenos físicos e químicos da matéria em escala nanométrica. A exploração do conhecimento da matéria em níveis tão ampliados demanda a utilização de técnicas aprimoradas de análise, surgidas principalmente nos últimos anos. Para o ramo dos materiais cimentícios, a Microscopia de Força Atômica (MFA) é tida em parte da literatura como a principal técnica voltada às análises e estudos no campo da nanociência. Contudo, para que funcione bem, a técnica demanda amostras altamente planas, o que se constitui um problema quando se trata de amostras de materiais cimentícios, de tendência naturalmente irregular e rugosa. Além disso, a técnica não realiza análise química da região varrida. Estas dificuldades são tratadas neste trabalho, que, como meta, procura contribuir com uma metodologia de preparo de amostras para análise no microscópio de força atômica (MFA), bem como visa estudar a associação das análises realizadas no MFA àquelas realizadas no microscópio eletrônico de varredura (MEV), mantendo-se as mesmas regiões varridas, com o intuito de verificar a possibilidade de identificação química no MEV das regiões analisadas no MFA. Para o estudo foram utilizadas pastas com e sem sílica ativa, almejando-se também obter as principais diferenças de uma e outra nas imagens obtidas por MFA. Considerou-se satisfatória a preparação de amostras para MFA, o que permitiu a identificação, em escala nanométrica, da estrutura mais densa e mais complexa das pastas com sílica ativa em comparação às pastas contendo apenas cimento Portland. O trabalho também contribui com a descrição teórica da técnica de MFA, produzindo um conteúdo importante de revisão da literatura sobre o princípio e a aplicação da técnica, além de suas potencialidades.

Palavras-chave: nanociência, microscopia de força atômica, pastas, cimento Portland, sílica ativa.

\section{ABSTRACT}

It has been credited to nanoscience a prominent role of providing full understanding of the macroscopic behavior of materials, since this field of science is capable of conducting studies and distinguishing physical and chemical properties or phenomena of the matter in nanoscale. The exploitation of knowledge on such a large magnification of the matter requires the use of improved analytical techniques, which have arisen mainly in recent years. In the context of cementitious materials, Atomic Force Microscopy (AFM) is considered by the literature as one of the main techniques for analysis and studies in the field of nanoscience. However, to work well, the technique demands highly flat samples, which is a problem considering samples of cementitious materials, with a naturally irregular and rough tendency. In addition, the technique does not perform 
chemical analysis. These difficulties are dealt with in this work, which aims to contribute with a sample preparation for analysis in the atomic force microscope (AFM), as well as to study the association of the analyzes performed in the AFM to those carried out in the scanning electron microscope (SEM), with the same regions being scanned, in order to verify the possibility of chemical identification by means of SEM of the regions analyzed by AFM. For the study, cement pastes with and without silica fume were used, aiming also to obtain the main differences of one and another in the images obtained by AFM. The sample preparation for AFM was considered satisfactory, which allowed the nanoscale identification of the denser and more complex structure of the pastes with silica fume compared to pastes containing only portland cement. The work also contributes to the theoretical description of the AFM technique, producing an important content in terms of literature revision on the principle and application of the technique, besides its potentialities.

Keywords: nanoscience, atomic force microscopy, pastes, portland cement, silica fume.

\section{INTRODUÇÃO}

Qualquer progresso relativo aos materiais resulta do conhecimento de suas propriedades ao nível microestrutural [1]. Seguindo esta afirmativa, quanto menor a escala utilizada maiores as possibilidades de análise, uma vez que ocorre ampliação a um nível no qual se inicia grande parte das interações e processos responsáveis pela definição das características e propriedades macroestruturais dos materiais, isto é, ao nível dos átomos e de suas interações - ramo explorado pela nanociência, que se dedica ao estudo das propriedades e dos fenômenos que ocorrem com a matéria em escala da ordem do nanômetro $\left(10^{-9} \mathrm{~m}\right)$, próximo ao nível dos átomos e de suas ligações.

A nanociência e a nanotecnologia têm avançado muito nos últimos anos, no entanto, de acordo com GLEIZE [2], a nanotecnologia aplicada aos materiais de construção ainda está em um estágio embrionário. Dentre os materiais de construção, os concretos (além das argamassas e pastas), por possuírem nanoestruturas complexas contendo produtos hidratados do cimento, são excelentes candidatos à manipulação e à definição e controle de suas propriedades por meio da nanociência [3].

No contexto científico, tem sido de suma importância o aparecimento de técnicas de análise aprimoradas que permitiram compreender melhor a estrutura interna dos materiais, como os microscópios de varredura por sonda (SPM, do inglês scanning probe microscope), que são equipamentos que não empregam um feixe de elétrons na análise e sim utilizam uma ponteira que varre a amostra. Dentre essas técnicas de varredura por sonda está a microscopia de força atômica - MFA (do inglês, atomic force microscopy - AFM), criada em 1986, a qual é capaz de realizar análises em escala atômica [4]. Nesse sentido, SCRIVENER [5] afirma que a microscopia de força atômica é uma das técnicas de microscopia mais promissoras para a avaliação da estrutura interna dos materiais cimentícios.

No caso específico de pesquisas com materiais à base de cimento, os microscópios de força atômica têm sido bastante utilizados em nanoindentação, visando avaliar as características físicas e mecânicas (em especial a dureza superficial e o módulo de elasticidade) em nanoescala, principalmente da fase C-S-H da pasta de cimento [6]. Nesta temática, além de diversos trabalhos internacionais, como os produzidos por IBARRA et al. [7], JENNINGS et al. [8], MONDAL et al. [9], VAN DAMME et al. [10] e CHEN et al. [11], podem ser citados os trabalhos nacionais de PELISSER [3] e SOUZA [12]. No entanto, poucos trabalhos têm sido realizados utilizando MFA para caracterização da micro e nanoestrutura da pasta de cimento das argamassas e dos concretos, com o detalhamento das características morfológicas, incluindo a forma e o tamanho de feições em nanoescala [6].

Assim, com o intuito de contribuir com este tema ainda pouco explorado no âmbito da caracterização nanoestrutural de materiais à base de cimento, o presente trabalho traz, inicialmente, um referencial teórico versando sobre o princípio, fundamentos, aplicabilidade e potencialidades da técnica de microscopia de força atômica, como forma de subsidiar a análise deste trabalho, bem como de outras pesquisas que venham a utilizar a referida técnica no âmbito da nanociência e nanotecnologia dos materiais. Além disso, com base em uma pesquisa experimental exploratória, procurou-se neste trabalho propor e avaliar uma metodologia de preparo de amostras de pasta de cimento para análise no MFA, empregando-se um molde contendo uma base plana e nivelada constituída de mica mineral recém-clivada. O estudo experimental também visou confrontar as análises realizadas no MFA às análises realizadas no microscópio eletrônico de varredura (MEV), mantendo-se as mesmas regiões varridas, com o intuito de verificar a possibilidade complementar de caracterização química com a identificação dos elementos presentes nas pastas por meio da Espectroscopia de Energia Dispersiva (EDS) das regiões analisadas no MFA. Para o estudo foram utilizadas pastas de cimento com e sem sílica ativa, com o intuito de produzir nano e microestruturas diferentes, capazes de serem diferenciadas por MFA e por MEV. 


\section{PRINCÍPIOS E FUNDAMENTOS DA TÉCNICA DE MICROSCOPIA DE FORÇA ATÔMICA}

A microscopia de força atômica, criada por Binnig, Quate e Gerber [4], é um tipo de microscopia de varredura por sonda, cujas principais vantagens de utilização estão fundamentadas nos seguintes aspectos: na possibilidade de se realizar análises em atmosfera controlada ou não e em meio líquido; na resolução de centenas de vezes superior às máximas obtidas pelos microscópios eletrônicos; e no custo operacional inferior aos microscópios eletrônicos comercialmente disponíveis.

São várias as microscopias classificadas como de varredura por sonda: a microscopia de tunelamento por varredura (MTV), a microscopia de força atômica (MFA), a microscopia óptica de varredura de campo próximo (do inglês, SNOM) e todas as derivadas destas; cada uma fornecendo diferentes informações, porém com semelhanças entre si. Dentre todas as técnicas desta categoria, destaca-se a MFA como a de maior potencial para aplicação em materiais cimentícios [5].

O princípio da técnica de MFA é o da medida das deflexões sofridas por uma haste em balanço (sonda) de massa ultrapequena, denominada cantilever, que ocorrem devidas à interação de forças, em nível atômico, entre a superfície amostrada e a ponteira ultra delgada que há na extremidade dessa haste, durante a condução da varredura. A quantificação dessas forças é permitida pela correlação entre as deflexões medidas e as propriedades características do material que compõe o cantilever, tendo em vista o alto nível de sensibilidade apresentado pelo microscópio [4].

À medida que a amostra varre, os deslocamentos sofridos pelo cantilever são determinados pela Lei de Hooke (Equação 1) e a frequência de ressonância pela Equação 2, sendo o cantilever tratado como uma mola. Para uma adequada funcionalidade, duas exigências devem ser atendidas pelo cantilever: máximo deslocamento para uma dada força de interação, isto é, reduzida rigidez $(\mathrm{k})$; e alta frequência de ressonância $\left(\mathrm{f}_{0}\right)$, a fim de minimizar os efeitos de possíveis vibrações originadas principalmente por ruídos internos e externos ao aparelho $[4,13]$.

$$
\begin{gathered}
F=k \cdot x \\
f o=\left(\frac{1}{2 \pi}\right) \cdot\left(\frac{k}{m_{0}}\right)^{\frac{1}{2}}
\end{gathered}
$$

Em que:

$F$ : força que interage com a ponteira;

$k$ : constante da "mola" (do cantilever), associada à sua rigidez;

$x$ : deflexão do cantilever (deslocamento da ponta livre do cantilever);

$f_{0}$ : frequência de ressonância do cantilever;

$m_{0}$ : massa do conjunto (cantilever e ponteira).

Programas computacionais específicos geram o mapa tridimensional das forças de interação ao longo da superfície varrida, bem como convertem os dados obtidos em imagens tridimensionais, representando a superfície da amostra em nível atômico. Um modelo esquemático de um microscópio de força atômica é mostrado na Figura 1.

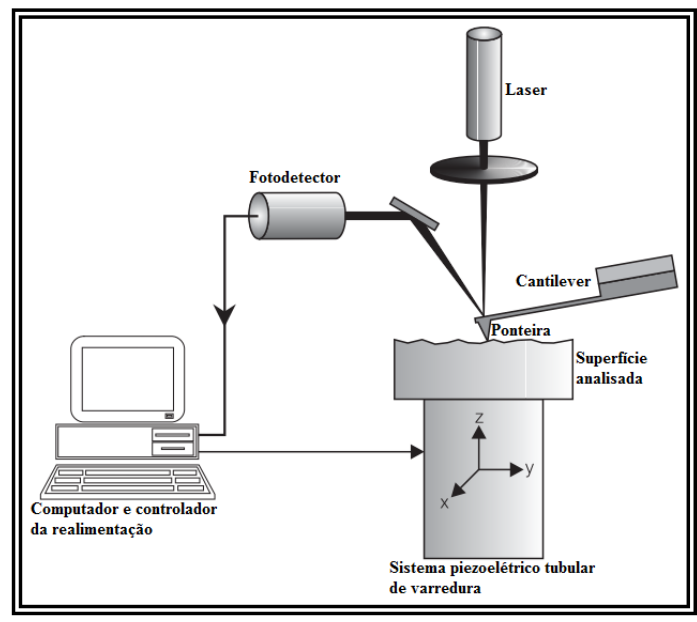

Figura 1: Modelo esquemático do microscópio de força atômica [14]. 
O cantilever e a ponteira são os elementos sensores dos microscópios de varredura por força. A ponteira, colocada no final do cantilever, mapeia a amostra. O cantilever mede a força de interação entre a amostra e a ponteira. Para imagens de topografia normal, a ponteira é colocada em contato contínuo ou intermitente com a amostra, sendo varrida ou arrastada sobre a sua superfície. O cantilever é usualmente constituído de uma ou mais hastes de silício ou nitreto de silício, que tem comprimento de $100 \mu \mathrm{m}$ a $500 \mu \mathrm{m}$ e espessura de $0,5 \mu \mathrm{m}$ a $5 \mu \mathrm{m}$. A ponteira possui alguns micrômetros de comprimento e diâmetro menor que $400 \AA$. O cantilever deve possuir um baixo valor de constante de mola, que seja menor do que a constante de mola efetiva que mantém os átomos da amostra juntos, o que está em geral em torno de $10 \mathrm{~N} / \mathrm{m}$. A constante de mola do cantilever do microscópio é determinada pelas propriedades geométricas (comprimento, largura e espessura) e pelo módulo de elasticidade do material do cantilever. Na prática, existem cantilevers comerciais com uma variedade de constantes de mola, desde $0,01 \mathrm{~N} / \mathrm{m}$ até $100 \mathrm{~N} / \mathrm{m}$, oferecendo uma vasta gama de opções de medida para uma infinidade de materiais [14].

O sistema de varredura é outro elemento determinante da resolução do microscópio. Este é formado por um sistema piezoelétrico, que gera a movimentação necessária (x, y e z) para obtenção de imagens topográficas nas três dimensões e medidas de força. O sistema piezoelétrico é um dispositivo que se move em escala nanométrica/micrométrica quando uma voltagem é aplicada entre seus eletrodos. Os sistemas de varredura são usados também para transladar a amostra até o cantilever ou o cantilever até a amostra. Os sistemas de varredura piezoelétricos para o microscópio podem transladar em três direções de forma a varrer dimensões desde alguns angströns até centenas de micrômetros nos eixos x e y, e de décimos de angströns a alguns micrômetros no eixo vertical z [13,14].

A medida de força e a obtenção das imagens é realizada registrando-se o deslocamento da ponta livre do cantilever quando esta é atraída ou repelida pela amostra. O método de detecção utilizado na maioria dos microscópios de força atômica comerciais é o da reflexão do feixe de laser. Este sistema mede o deslocamento do cantilever por meio da incidência e reflexão de um feixe de laser na ponta livre espelhada do cantilever. A maioria dos equipamentos comerciais utiliza laser com comprimento de onda de $650 \mathrm{~nm}$ e potência de 5 $\mathrm{mW}$. As deflexões do cantilever causam uma mudança no ângulo de reflexão do feixe de laser, que após refletir em um espelho, é detectado por um fotodiodo de segmento múltiplo. A sensibilidade da medida vertical depende do comprimento do cantilever, ou seja, para uma mesma deflexão vertical, um cantilever mais curto produz uma deflexão angular menor do que um longo [14].

Nos sistemas comerciais, a distância entre a amostra e a sonda é mantida constante ou oscilando entre valores constantes por meio da variação da tensão aplicada no piezoelétrico no eixo z. Como as mudanças no piezoelétrico não são instantâneas, o sistema de realimentação controla o deslocamento em z para que ele ocorra da maneira mais fiel possível. As operações de controle e realimentação, assim como a aquisição de dados, construção e processamento das imagens são realizados pelo computador [14].

Os microscópios de varredura por força não se limitam à obtenção de imagens, mas são técnicas poderosas que permitem a análise de forças e propriedades em escala nanométrica. Nesse sentido, para melhor se explorar o potencial destas técnicas é importante conhecer os chamados modos de operação do microscópio, pois estes determinam os tipos de forças envolvidas e, desta forma, as características possíveis de serem analisadas na amostra em questão.

Vários tipos de forças contribuem para a deflexão de um cantilever em um microscópio de força atômica. A Figura 2 ilustra de forma simplificada as forças envolvidas, de acordo com a distância que separa a ponteira da amostra. A curva de força em função da distância é outra possibilidade de se analisar esta interação. Na Figura 3, pode-se observar esta relação, que permite avaliar o regime e o modo de trabalho do sistema $[15,16]$. 


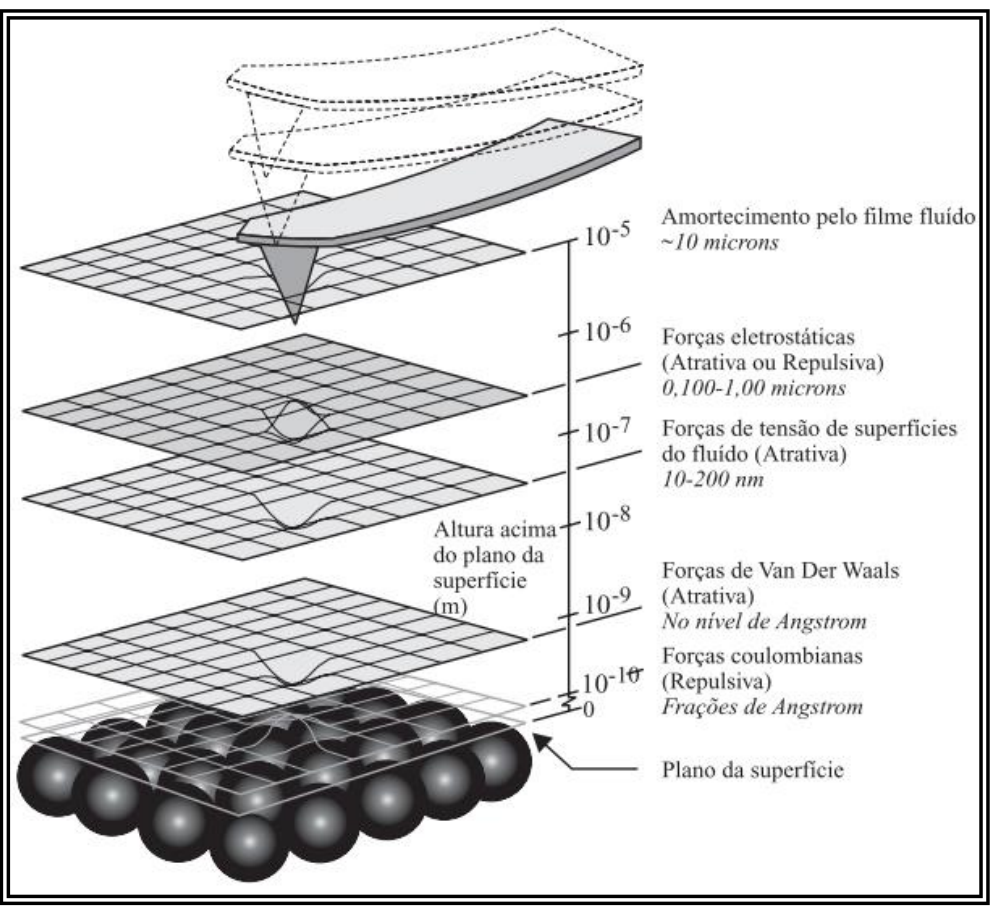

Figura 2: Relação de forças que atuam entre a ponteira e a amostra em função da distância que as separa [17].

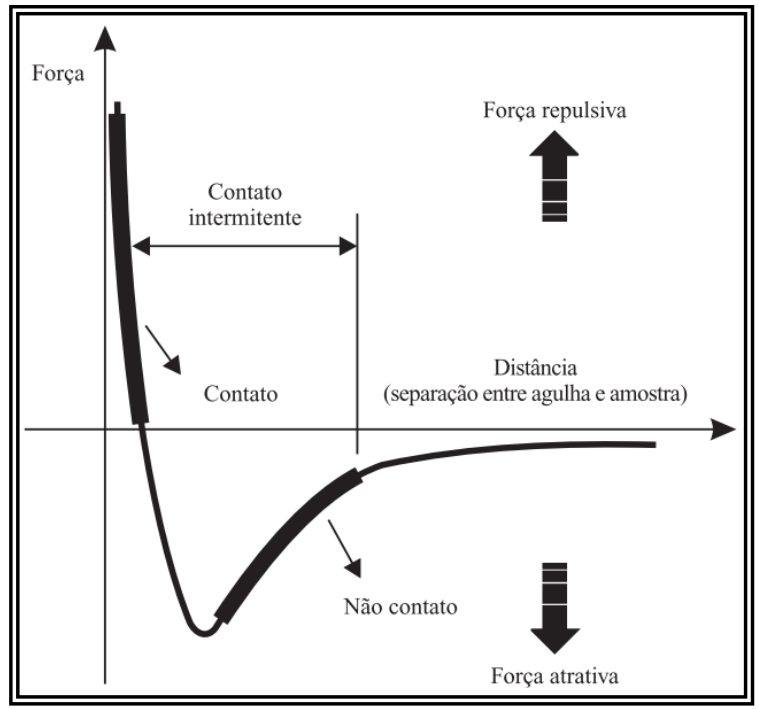

Figura 3: Curva da força pela distância de separação entre a ponteira e a amostra [17].

Para dois corpos eletricamente neutros e não magnéticos separados por uma ou várias dezenas de nanômetros, pode-se dizer que as forças de Van der Waals geralmente dominam a interação entre eles. Estas forças são consideradas atrativas. Diminuindo a distância de separação entre os dois corpos, para alguns angströns, as forças que irão dominar serão as forças repulsivas, isto se deve principalmente à componente de força coulombiana. Dessa forma, a distância ponteira-amostra determina o modo de operação do microscópio, que pode ser: contato, não-contato e contato intermitente [14].

O modo contato é o modo mais básico de operação do microscópio. Nele, a ponteira varre a amostra mantendo a menor distância possível na faixa das distâncias interatômicas. As forças envolvidas são de repulsão, sendo necessário um criterioso cuidado para que a ponteira não danifique a amostra. A força realizada pela ponteira é calculada multiplicando-se a deflexão do cantilever pela sua constante de mola. Neste modo a pequena força repulsiva entre a ponteira e a amostra é da ordem de $10^{-6} \mathrm{~N}$ a $10^{-9} \mathrm{~N}$, o que exige um sistema com boa sensibilidade para detectar a deflexão do cantilever [18]. 
O modo não-contato explora outros níveis de interação de força. Este método é sensível ao gradiente de força e oferece vantagem significativa quando comparado ao modo contato para medidas de deflexão do cantilever usado para o estudo das forças de longo alcance. A força total entre a ponteira e a amostra, neste modo, geralmente está em torno de $10^{-12} \mathrm{~N}$, menor do que no modo contato, minimizando assim o contato físico ponteira-amostra e, consequentemente, evitando que a amostra sofra deformação. $\mathrm{O}$ método baseia-se na separação da ponteira em relação à amostra em, aproximadamente, $10 \mathrm{~nm}$ a $100 \mathrm{~nm}$. Somente forças de interação de longo alcance irão interagir, no caso as forças de Van der Waals, as forças de natureza eletrostática e forças de dipolo magnético. O método para a medida da interação de força no modo não-contato com o microscópio é geralmente diferente do modo contato. Naquele caso, ao invés de medir a deflexão do cantilever quase estático, este é colocado para vibrar próximo de sua frequência de ressonância pelo uso de um elemento piezoelétrico. Mudanças no valor da frequência de ressonância ocorrerão devidas ao resultado da força de interação entre a ponteira e a superfície analisada $[4,19]$.

$\mathrm{O}$ princípio de funcionamento do modo contato intermitente, quasi non-contact ou tapping mode é similar ao sistema de trabalho do não-contato, isto é, o cantilever vibra, por intermédio de um sistema piezoelétrico próximo à sua frequência de ressonância. $\mathrm{O}$ cantilever juntamente com a ponteira é colocado bem próximo à amostra até que o deslocamento contínuo e controlado do piezoelétrico faça com que a ponteira toque levemente a amostra. A ponteira oscila com uma amplitude de vibração do cantilever entre $20 \mathrm{~nm}$ e $100 \mathrm{~nm}$, mas somente "toca" a amostra por um breve período do tempo total de vibração. Durante uma varredura, a oscilação vertical da ponteira entra em contato com a amostra por um curtíssimo período de tempo e salta para fora da amostra com uma frequência de 50000 a 500000 vezes por segundo. Esta técnica vem sendo aplicada com bons resultados em alguns tipos de amostras consideradas macias, como, por exemplo, polímeros e materiais biológicos, pois ao contrário do modo contato, o modo contato intermitente elimina basicamente a influência da força lateral que pode deformar ou até danificar a amostra. Quando comparada com o modo não-contato, a técnica de contato intermitente torna-se mais efetiva por realizar imagens de grandes áreas, que podem incluir maiores variações na topografia da amostra. Alguns aparelhos permitem explorar a detecção de fase e, dada a sensibilidade da técnica, é possível extrair novas informações da imagem, como, por exemplo, diferenças entre módulos de elasticidade das fases presentes [14,17].

Além desses três modos de operação do microscópio apresentados, que são os mais usuais, existem vários outros modos, tais como: força lateral, força química, força modulada, força elétrica, força magnética e força térmica, como destacado por HERRMANN et al. [14].

\section{MATERIAIS E MÉTODOS}

Pastas de cimento Portland, com e sem adição de sílica ativa, foram produzidas para análise ao microscópio de força atômica. Complementarmente, empregou-se a microscopia eletrônica de varredura (MEV), visando à identificação dos produtos de hidratação por meio das microanálises com EDS. Na sequência, são apresentados os materiais utilizados, bem como os detalhes da metodologia adotada.

\subsection{Materiais utilizados}

Os materiais utilizados na preparação das pastas foram o cimento Portland do tipo CP V - ARI e uma sílica ativa com área específica BET igual a $15990 \mathrm{~m}^{2} / \mathrm{kg}$, além da água (proveniente da rede de abastecimento público). A caracterização dos materiais está apresentada na Tabela 1.

Tabela 1: Caracterização química do cimento CP V - ARI e da sílica ativa utilizados na produção das pastas.

\begin{tabular}{c|c|c}
\hline CONSTITUINTES QUÍMICOS & CP V - ARI (\%) & SíliCA ATIVA (\%) $^{*}$ \\
\hline $\mathrm{SiO}_{2}$ & 20,82 & 91,05 \\
\hline $\mathrm{Al}_{2} \mathrm{O}_{3}$ & 5,04 & 0,17 \\
\hline $\mathrm{Fe}_{2} \mathrm{O}_{3}$ & 2,56 & 0,30 \\
\hline $\mathrm{CaO}$ & 65,66 & 0,77 \\
\hline $\mathrm{MgO}$ & 1,40 & 0,75 \\
\hline $\mathrm{SO}_{3}$ & 1,52 & 0,52 \\
\hline $\mathrm{K}_{2} \mathrm{O}$ & 1,04 & 0,27 \\
\hline $\mathrm{Na}_{2} \mathrm{O}$ & 0,09 & 0,21 \\
\hline Outros óxidos & 1,87 & 5,96 \\
\hline
\end{tabular}

* porcentagem em relação à massa total. 
Na Figura 4 é apresentado o difratograma de raios X do cimento Portland CP V - ARI, por meio do qual foram constatadas as seguintes fases cristalinas principais, constituintes do material: silicato tricálcico $\left(\mathrm{C}_{3} \mathrm{~S}\right)$, silicato dicálcico $\left(\beta \mathrm{C}_{2} \mathrm{~S}\right)$, aluminato tricálcico $\left(\mathrm{C}_{3} \mathrm{~A}\right)$ e ferroaluminato tetracálcico $\left(\mathrm{C}_{4} \mathrm{AF}\right)$. Além destes constituintes de Bogue, oriundos do clínquer, aparece o carbonato de cálcio $\left(\mathrm{CaCO}_{3}\right)$, decorrente do teor de material carbonático (fíler calcário) admitido no cimento, assim como há algumas ocorrências de óxidos e traços de uma fase hidratada, o hidróxido de cálcio.

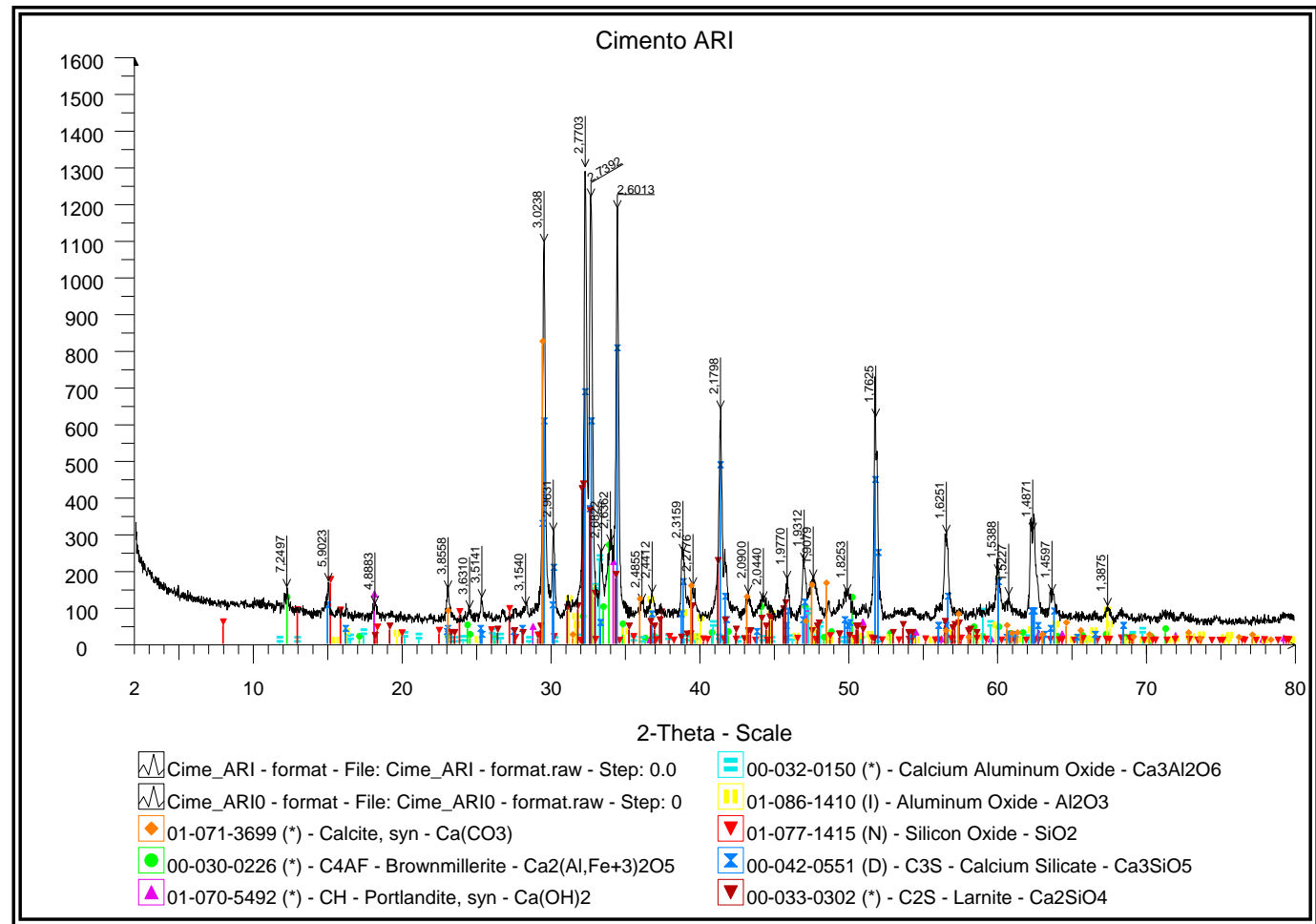

Figura 4: Difratograma de raios X do cimento Portland CP V - ARI.

O difratograma da sílica ativa está apresentado na Figura 5. Nele, verifica-se o perfil de um material essencialmente amorfo, de baixa cristalinidade. É possível observar uma banda amorfa, de ocorrência típica na sílica ativa. 


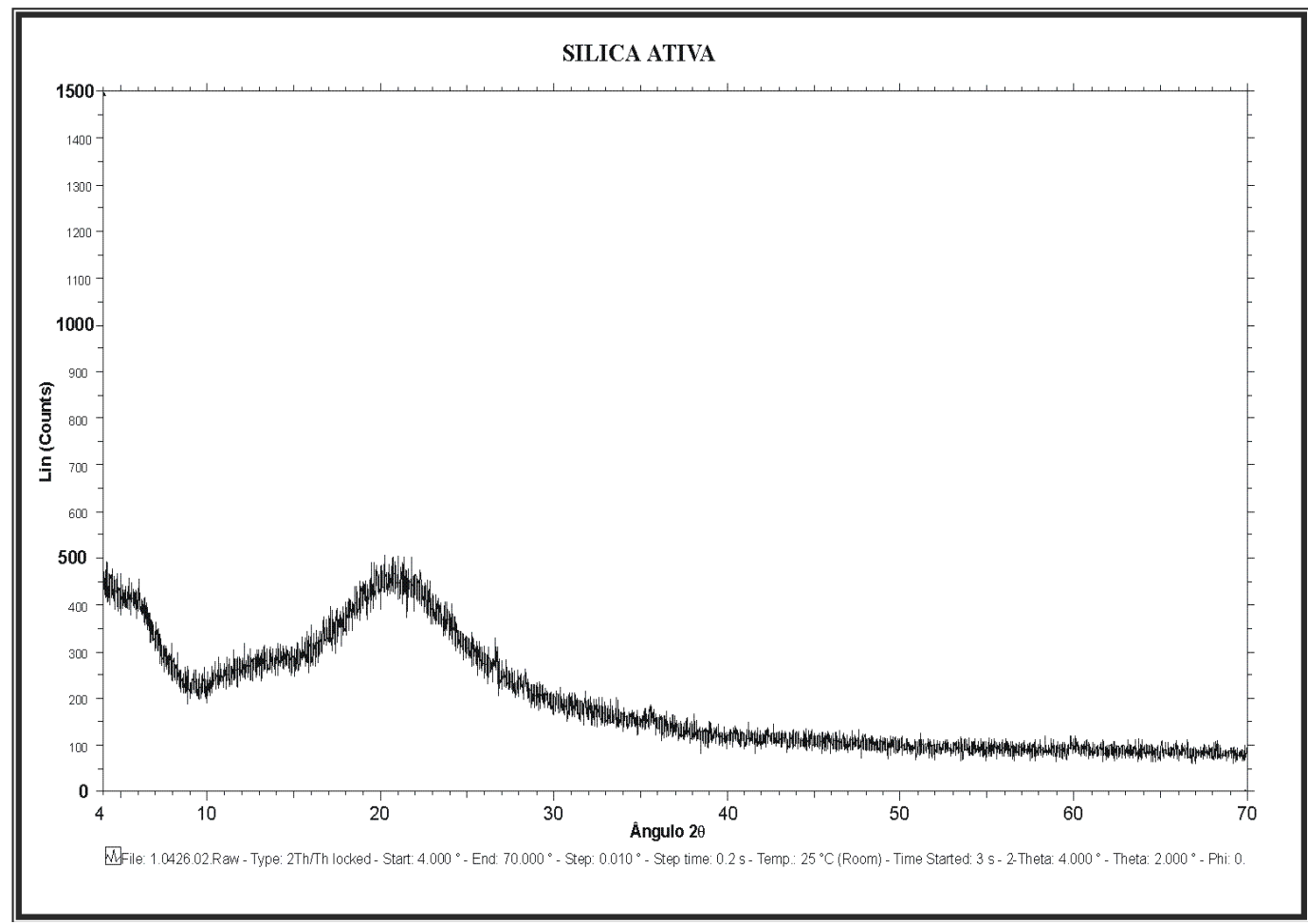

Figura 5: Difratograma de raios $X$ da sílica ativa.

\subsection{Preparo das pastas, moldes e acondicionamento das amostras}

Foram estudadas pastas de relação água/ligante, em massa, igual a 0,45. A sílica ativa foi utilizada na mistura em substituição ao cimento no teor de $10 \%$, em massa. Para a pasta que não continha adição mineral, primeiramente foi colocado o cimento Portland em um becker, seguido da colocação da água e de uma mistura manual durante três minutos. No caso da pasta contendo sílica ativa, primeiramente foi colocada a adição mineral no becker, em seguida a água e estes materiais foram misturados manualmente por dois minutos, período após o qual foi colocado o cimento Portland e uma nova mistura manual foi realizada por mais três minutos.

A moldagem das pastas para o microscópio de força atômica demandou um estudo piloto, a partir do qual foi obtido um procedimento padrão de moldagem que funcionou adequadamente para as análises pretendidas. A necessidade deste estudo deveu-se à exigência, por parte do equipamento, de alta planicidade e nivelamento da superfície amostrada, características naturalmente não apresentadas pelo material analisado. De antemão, respaldado pelos trabalhos encontrados na literatura, em especial com base no trabalho de YANG et al. [20], decidiu-se pela moldagem das pastas sobre placas de mica recém-clivadas. A definição do molde exigiu, então, alguns ajustes, tendo-se evoluído para o procedimento final, descrito na sequência.

Adotou-se, portanto, um tubo cilíndrico de PVC de uma polegada de diâmetro, que foi cortado em pequenos cilindros de $3 \mathrm{~mm}$ de altura em uma torneadora mecânica com corte de precisão, visando-se atingir o nivelamento exigido pelo microscópio. Esses cilindros foram preenchidos com pasta, tendo sido moldados com uma face sobre uma placa de mica recém-clivada, a fim de que fosse atingida a planicidade necessária. Por meio deste procedimento, foram obtidas boas imagens, pouco ruidosas e com nitidez. Na Figura 6 podem ser vistos um cilindro de PVC (molde) e uma placa de mica recém-clivada utilizados para moldar as pastas analisadas no microscópio de força atômica. Ressalta-se que a clivagem ou a extração de cada uma das camadas de mica era obtida colando-se fita adesiva de dupla-face sobre a placa e, posteriormente, puxando-a; cada vez que se puxava, uma camada era extraída. A clivagem da mica foi realizada visando-se garantir que a superfície do mineral estivesse perfeitamente limpa. 


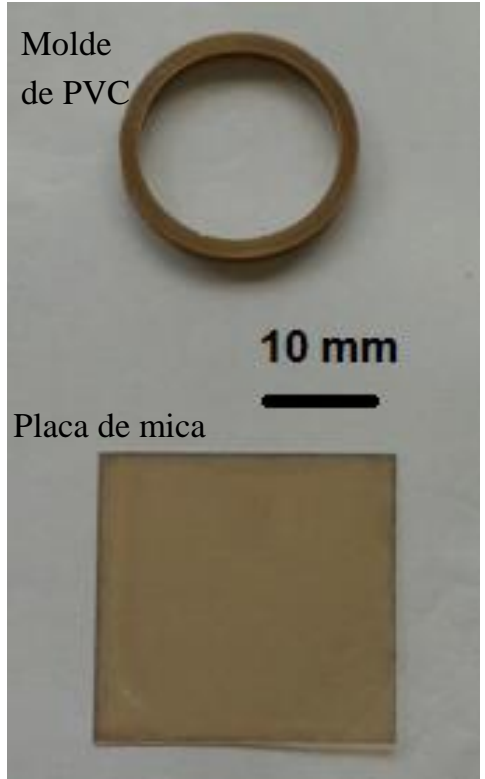

Figura 6: Molde cilíndrico de PVC obtido em torneadora mecânica com corte de precisão e placa de mica recém-clivada utilizados para moldagem das pastas analisadas no microscópio de força atômica.

Após a mistura das pastas e a sua consequente introdução nos moldes cilíndricos, procedeu-se à sua desmoldagem com 24 horas. Na sequência, elas foram acondicionadas em um dessecador hermeticamente fechado, contendo em seu interior cal sodada e sílica gel. Esta forma de acondicionar as amostras evitou os efeitos indesejáveis de uma carbonatação prematura das pastas pela absorção do gás carbônico por meio da cal sodada e da umidade ambiente por intermédio da sílica gel. Após 28 dias da moldagem, as pastas foram analisadas.

\subsection{Métodos e análises realizadas}

Inicialmente as pastas foram analisadas no microscópio de força atômica (MFA) e depois as mesmas pastas foram analisadas ao microscópio eletrônico de varredura (MEV), nas mesmas regiões varridas preliminarmente pelo MFA. Este procedimento foi necessário porque se pretendia obter as imagens dos compostos hidratados das pastas em escala nanométrica - o que era obtido pela técnica de MFA - bem como a identificação dos elementos presentes - o que era obtido via MEV. A definição desta sequência das técnicas esteve relacionada às características necessárias de preparação de amostra para cada equipamento. Não poderia ser contrária a ordem de realização das análises, a saber: MEV depois MFA, porque na microscopia eletrônica de varredura é necessário o recobrimento das amostras com material condutor e isto poderia levar a obtenção de informações sobre a camada de recobrimento e não sobre a superfície da pasta no MFA.

\subsubsection{Análise no microscópio de força atômica}

Para as análises no MFA, foi empregado um microscópio da marca Agilent Technologies, modelo 5500, como ilustrado na Figura 7. O modo de operação adotado foi o não-contato, para evitar qualquer tipo de contato entre a sonda e a superfície da amostra e, assim, evitar que a ponteira da sonda se quebrasse durante a análise, já que a pasta cimentícia é um material de natureza rugosa que apresenta dureza e resistência superficial elevadas. Para cada amostra, foram varridas regiões quadradas de $5 \mu \mathrm{m} \times 5 \mu \mathrm{m}$. As imagens foram posteriormente tratadas utilizando-se o software SPIP (Scanning Probe Image Processor) 6.6.5, da Image Metrology $A / S$. 


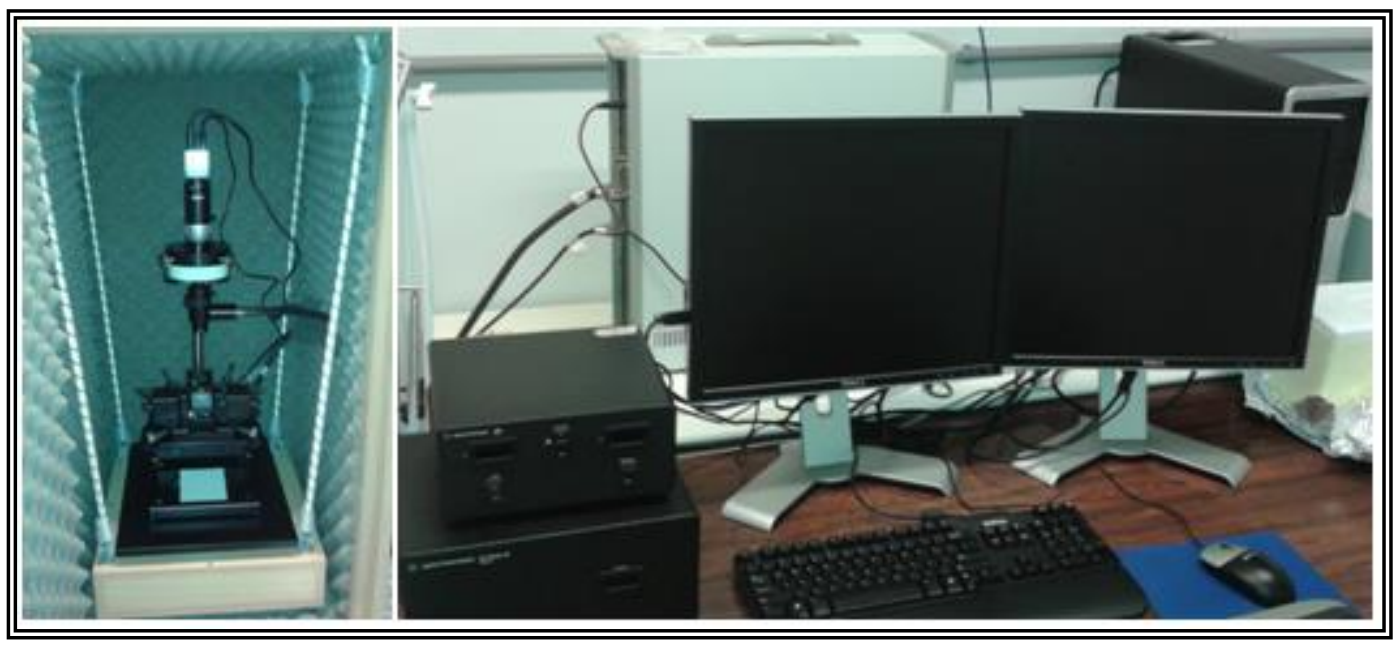

Figura 7: Microscópio de força atômica do Laboratório Multiusuário de Microscopia de Alta Resolução (LABMIC), da Universidade Federal de Goiás.

\subsubsection{Análise ao microscópio eletrônico de varredura}

A identificação dos elementos presentes nas regiões de cada amostra varrida pelo microscópio de força atômica foi realizada pelo microscópio eletrônico de varredura por meio da técnica de espectroscopia de energia dispersiva (EDS). Delimitava-se manualmente com um pincel marcador a região varrida no microscópio de força atômica, correspondente a quadrículos de aproximadamente $3 \mathrm{~mm} \times 3 \mathrm{~mm}$ e esta mesma região era analisada no microscópio eletrônico, conforme pode ser visto na Figura 8. As amostras foram secas em estufa, permanecendo em temperatura de $(100 \pm 5)^{\circ} \mathrm{C}$ por 48 horas. Em seguida, elas foram recobertas com material condutor utilizando-se um equipamento metalizador da marca Denton Vacuum, modelo Desk V, por meio do qual um fino filme de ouro, de aproximadamente $250 \AA$ de espessura, foi depositado sobre cada amostra em uma câmara com pressão atmosférica entre 50 mTorr e 60 mTorr e corrente de $15 \mathrm{~mA}$ durante dois minutos. O microscópio empregado foi da marca Jeol, modelo JSM 6610, equipado com um EDS Thermo Scientific NSS Spectral Imaging.

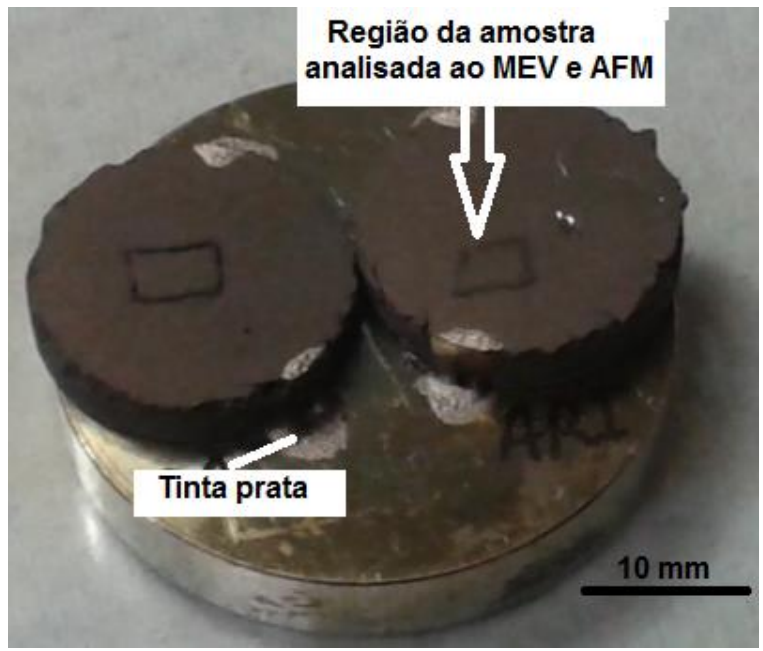

Figura 8: Delimitação com pincel da região das amostras analisadas por MFA (AFM no inglês) e MEV (ver quadrículos marcados). As amostras de pasta de cimento analisadas estão fixadas no porta amostras de alumínio e para garantir o contato elétrico da amostra com o porta amostra foi utilizada tinta prata.

\section{RESULTADOS E DISCUSSÃO}

São apresentados neste item os resultados de MFA e MEV obtidos para as pastas estudadas. Cada sequência horizontal de três imagens obtidas por meio de MFA refere-se à varredura realizada em uma mesma região, para a qual se apresentam, respectivamente, da esquerda para a direita, as informações de topografia, amplitude e perspectiva tridimensional. A imagem de topografia fornece informações sobre o relevo da amostra, de 
modo que quanto mais escura a imagem, menor a altura; a imagem de amplitude complementa as informações sobre o relevo fornecido pela imagem de topografia, por estar relacionada com a amplitude de vibração da ponteira ao longo da varredura; e, por fim, a imagem da perspectiva tridimensional é obtida a partir da concatenação das diversas alturas obtidas.

Na Figura 9, apresentam-se as imagens relativas às pastas de referência obtidas pela técnica de MFA, nas quais foram destacadas cinco distintas regiões da pasta de referência (Figuras 9a a 9e). Na primeira das regiões varridas (Figura 9a), percebe-se uma zona de contato (ligação) entre dois diferentes produtos da hidratação do cimento Portland, verificada por uma diferença de relevo entre fases. Na imagem, podem ser vistas duas regiões separadas por uma depressão, que, aparentemente, configura-se como um "canal" de separação dessas duas diferentes fases.

Este mesmo aspecto, de interface entre fases, é possível de ser visto na terceira e na quinta imagem (Figuras 9c e 9e). Nelas, igualmente à Figura 9a, são verificadas as variações de relevo (zonas mais e menos escuras na imagem de topografia), bem como as claras interfaces entre diferentes compostos (vistas nas imagens de amplitude e de perspectiva tridimensional). Em especial na Figura 9c, pode-se observar uma interface de uma fase mais lisa, provavelmente a superfície de uma placa de hidróxido de cálcio $(\mathrm{CH})$, com uma fase mais irregular ou desuniforme (em termos de relevo), indicativa de uma aglomeração de silicato de cálcio hidratado $(\mathrm{C}-\mathrm{S}-\mathrm{H})$.

Na segunda região varrida (Figura 9b), uma área nanometricamente plana foi observada, com variação máxima do relevo de $63 \mathrm{~nm}$. A imagem de amplitude sugere, também, a possibilidade de as pequenas esferas observadas representarem alguma alteração química sofrida superficialmente pelo produtode hidratação do cimento. O fenômeno mais provável é a alteração superficial do hidróxido de cálcio, após reação incipiente de carbonatação com o $\mathrm{CO}_{2}$ atmosférico durante a execução da análise, já que até o momento do ensaio a pasta esteve preservada da ação do $\mathrm{CO}_{2}$. Aspecto semelhante foi observado por YANG et al. [21] em pastas carbonatadas. Esses autores observaram também a existência de nanopartículas de $\mathrm{H}_{2} \mathrm{O}$ na superfície do $\mathrm{Ca}(\mathrm{OH})_{2}$, as quais garantem a ocorrência da reação de carbonatação. Como será comentado na sequência, com os resultados de MEV, a ocorrência predominante nas pastas foi de C-S-H e de $\mathrm{CH}$, sendo que, em virtude do uso de uma superfície plana de mica como molde, muitas das partículas de $\mathrm{CH}$ ficaram orientadas, resultando nessas superfícies planas vistas no MFA.

A quarta imagem (Figura 9d) parece referir-se à superfície de um composto único, cuja identificação, dada a similaridade das imagens obtidas por PELED e WEISS [22], possivelmente é de um C-S-H.

Na sequência são apresentados os resultados obtidos a partir de análises ao MEV (Figura 10), todas provenientes de regiões delimitadas pelo quadrículo de $3 \mathrm{~mm}$ x $3 \mathrm{~mm}$ dentro do qual também ocorreram as imagens no MFA. Destaca-se que o objetivo da demarcação de tal quadrículo foi identificar quimicamente no microscópio eletrônico de varredura, por meio de EDS, os produtos surgidos nas superfícies das regiões varridas pelo MFA. No entanto, esta meta não foi plenamente alcançada, pelo fato de a área demarcada ser excessivamente grande e tendo em vista a alta resolução dos equipamentos utilizados, o que, no entanto, não deixou de ter sido importante, porque informou sobre o panorama químico de tais regiões.

Pelas imagens da Figura 10, tem-se uma resposta em termos de ocorrência dos compostos precipitados na pasta de cimento da região anteriormente varrida e analisada por MFA, propiciando, assim, caracterizar química e mineralogicamente a amostra analisada. Essencialmente, silicato de cálcio hidratado $(\mathrm{C}-\mathrm{S}-\mathrm{H})$ e hidróxido de cálcio $(\mathrm{CH})$ foram os produtos identificados. É interessante observar (na Figura 10a e 10b) a maneira como apareceu o $\mathrm{CH}$, na forma de placas orientadas (“deitadas"), certamente pelo fato de a face da pasta analisada ter sido moldada sobre placa de mica, plana e lisa, o que forçou uma orientação preferencial das placas de CH. Dessa forma, as imagens dos produtos de hidratação no microscópio eletrônico de varredura do presente estudo nem sempre se apresentaram com as configurações típicas das imagens obtidas em amostras fraturadas. 

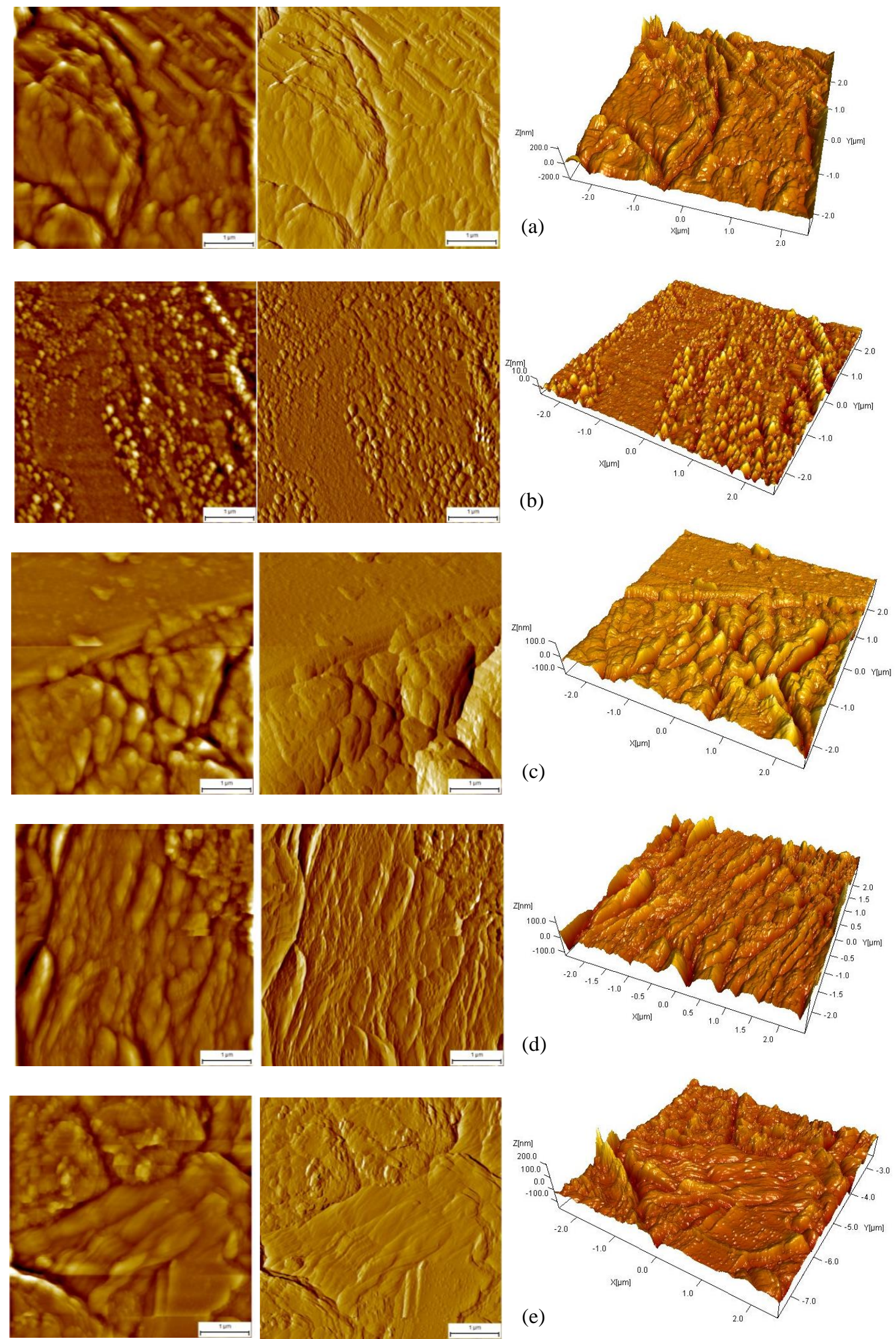

Figura 9: Imagens obtidas por MFA para a pasta de referência. 
(a)

(b)

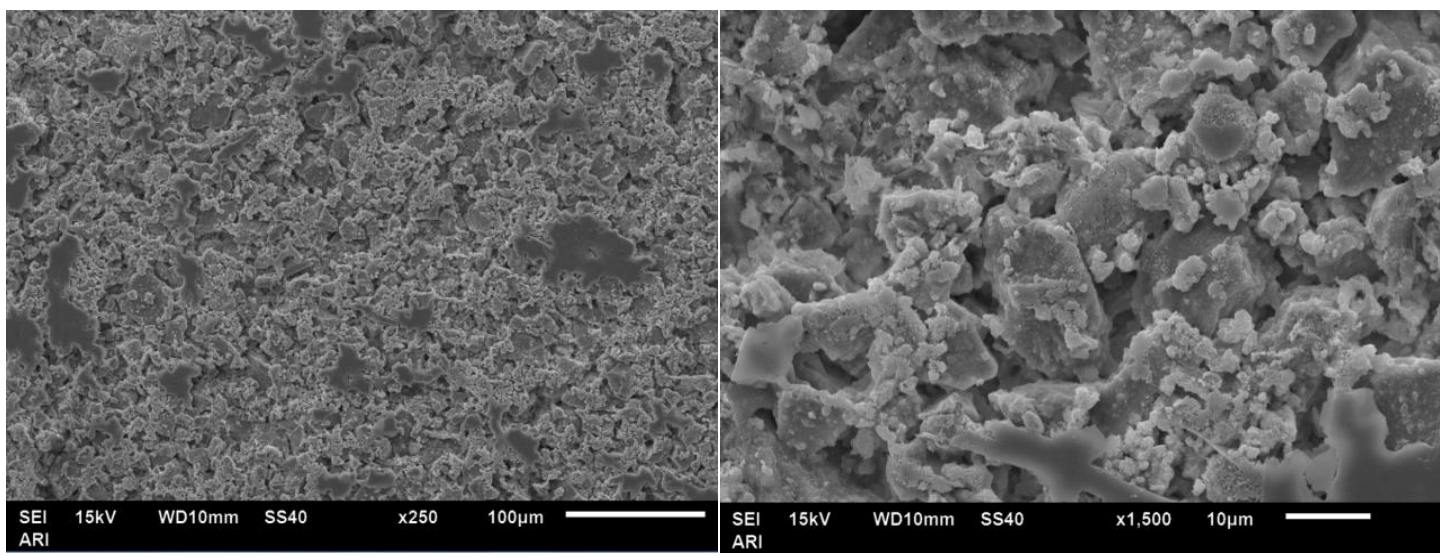

(c)
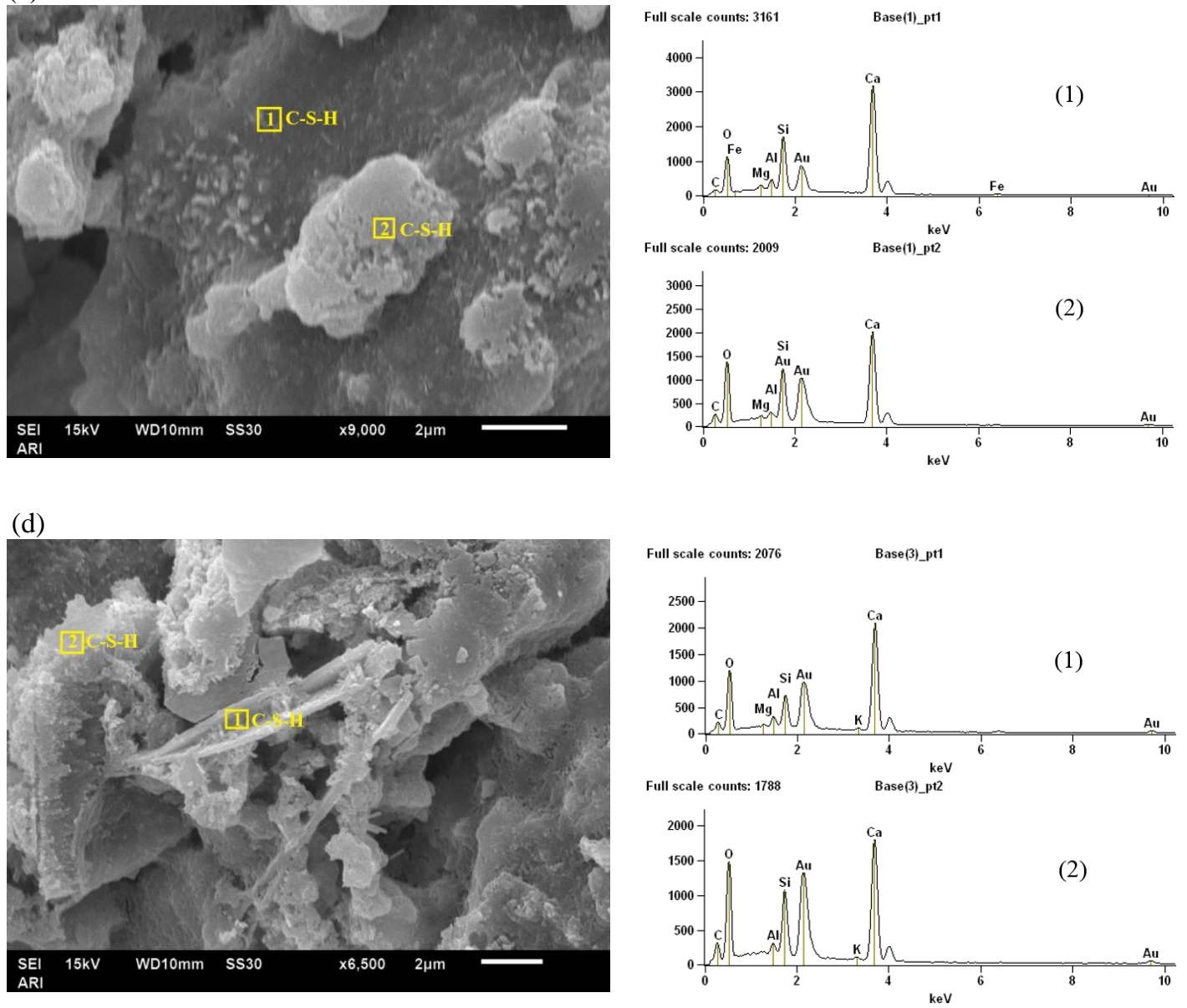
(e)
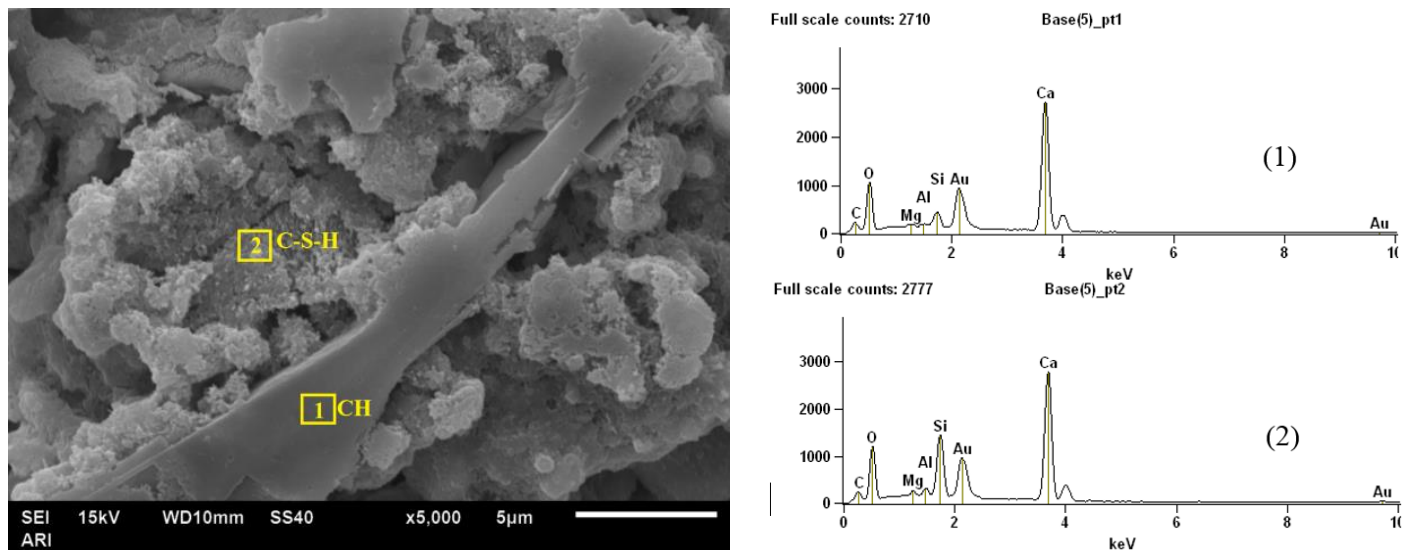

(f)
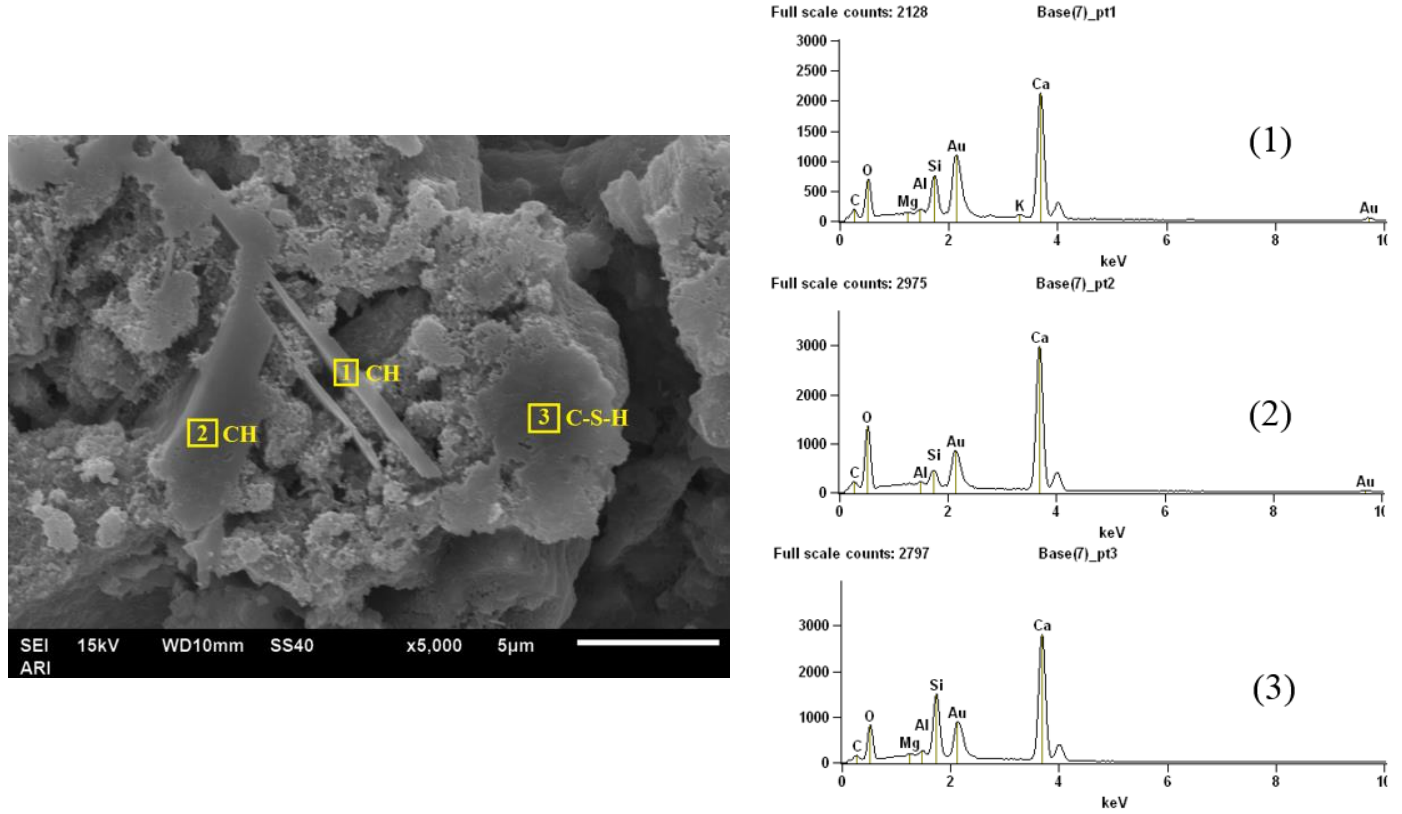

Figura 10: Imagens obtidas pelo microscópio eletrônico de varredura para a pasta de referência, acompanhadas dos espectros das microanálises realizadas por EDS.

Na Figura 11, apresentam-se as imagens obtidas por MFA para a pasta composta por cimento Portland e sílica ativa. Por representar um sistema de maior complexidade, com a adição de um material a mais que é a sílica ativa, as imagens refletem esse sistema mais complexo, ressaltando um maior conjunto de zonas de contato entre fases hidratadas. Sabe-se que na presença de uma pozolana (como a sílica ativa), há a formação de C-S-H adicional ou suplementar, com o consumo de hidróxido de cálcio da pasta. Com isso, embora se identifique uma maior quantidade de zonas de contato entre fases (quando se compara com um sistema mais simples, como na Figura 9), há, com efeito, uma densificação da pasta, mediante redução da porosidade total e tendo-se um refinamento de poros.

Como as estruturas individuais de C-S-H são partículas em nanoescala, descritas na literatura como lamelas dobradas ao acaso, estas ligam-se muito mais intensamente, por efeito atrativo de cargas elétricas superficiais ou por forças de Van de Waals, do que estruturas maiores como as placas de $\mathrm{CH}$ [23, 24, 25]. Em outras palavras, por possuírem alta superfície específica, as estruturas de C-S-H formam agregações fortemente ligadas, com alta capacidade ligante e de significativa contribuição à resistência mecânica da pasta, a despeito de produzirem imagens mais complexas, com topografia mais irregular e com uma maior quantidade de zonas de contato entre fases sólidas. As imagens da Figura 11, portanto, expressam tanto a maior complexidade quanto à maior compacidade e densificação da pasta em relação às imagens da Figura 9. Essas imagens também parecem expressar que as reações pozolânicas $(\mathrm{CH}$ com $\mathrm{Si}$ ) ainda não foram plenamente finalizadas na idade de análise das amostras (28 dias), o que também pode ser demostrado pela complexidade e heterogeneidade das imagens. 

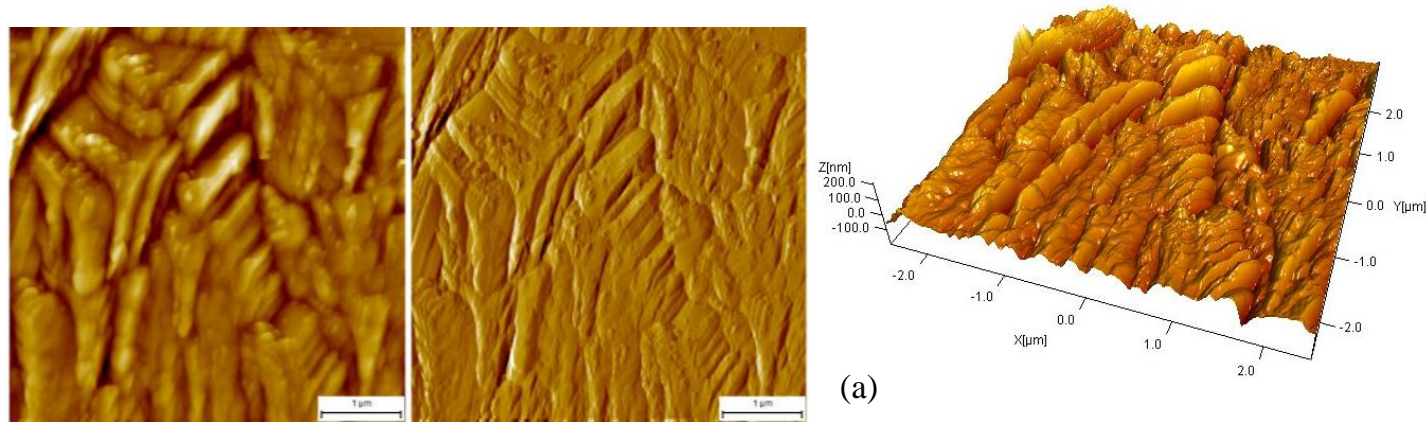

(a)
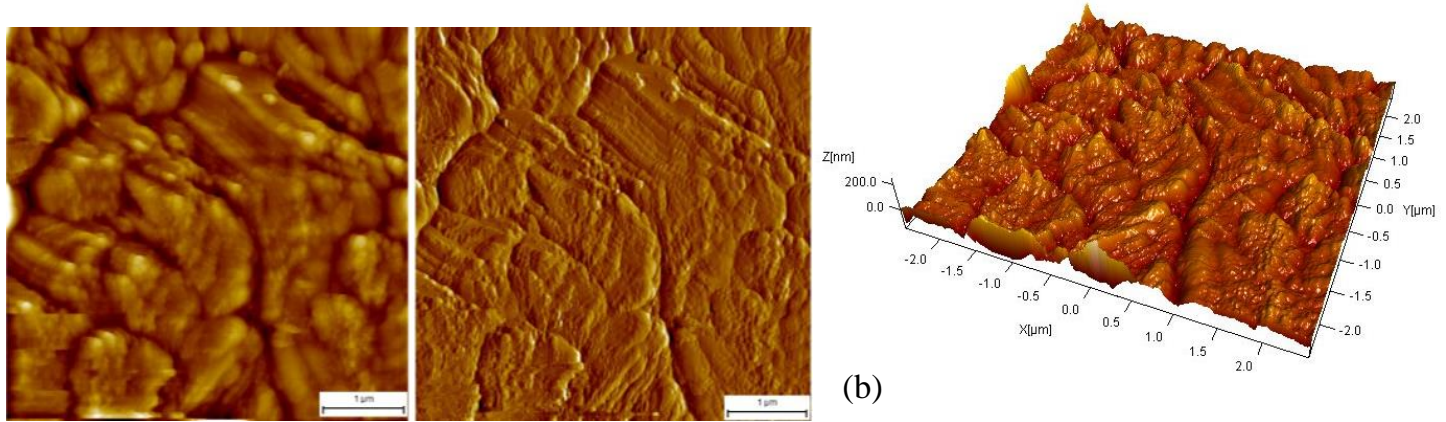

(b)
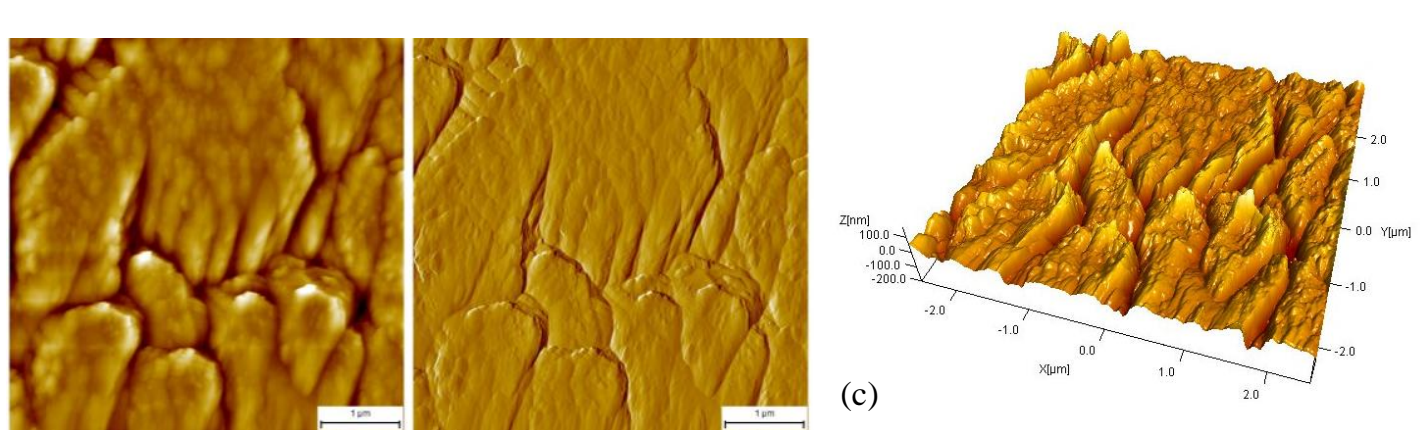

(c)

Figura 11: Imagens obtidas por MFA para a pasta constituída de cimento Portland e sílica ativa.

Esse efeito de densificação da pasta também pôde ser observado nas imagens obtidas por MEV, na Figura 12, na qual, comparativamente à Figura 10, visualiza-se, principalmente nas imagens (a) e (b), um aspecto microestrutural mais denso da pasta composta por sílica ativa em relação à de referência. Concernente às análises complementares de caracterização realizadas por EDS, foram identificadas as mesmas fases presentes na pasta só de cimento e água (Figura 10), a saber: C-S-H e CH; contudo, foi notória a maior ocorrência relativa de C-S-H, o que explica a maior compacidade da pasta contendo sílica ativa (em relação à pasta contendo apenas cimento e água). Ainda assim, verificou-se a presença de $\mathrm{CH}$ nessas pastas com sílica ativa, como se pode observar nas imagens (d), (e) e (f) da Figura 12, mas não foi possível a identificação de fases aluminato como a etringita (trissulfoaluminato de cálcio hidratado - $\mathrm{AFt}$ ) ou o monossulfato (monossulfoaluminato de cálcio hidratado - AFm). 
(a)

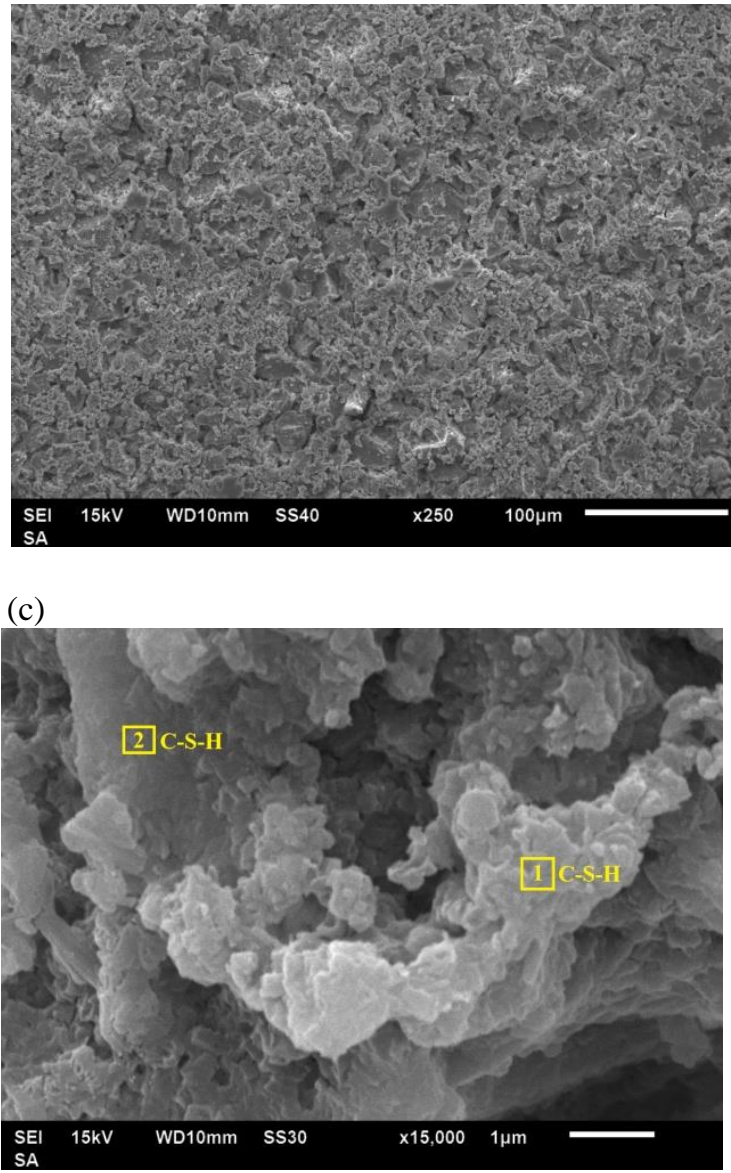

(d)

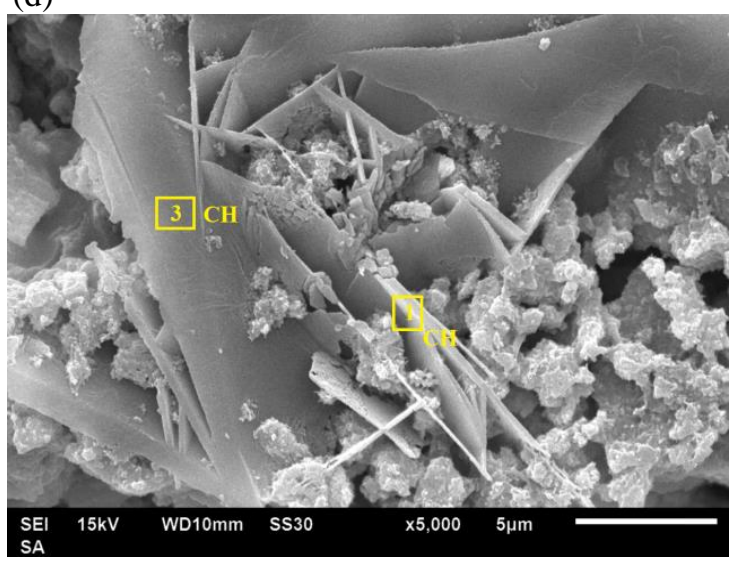

(b)
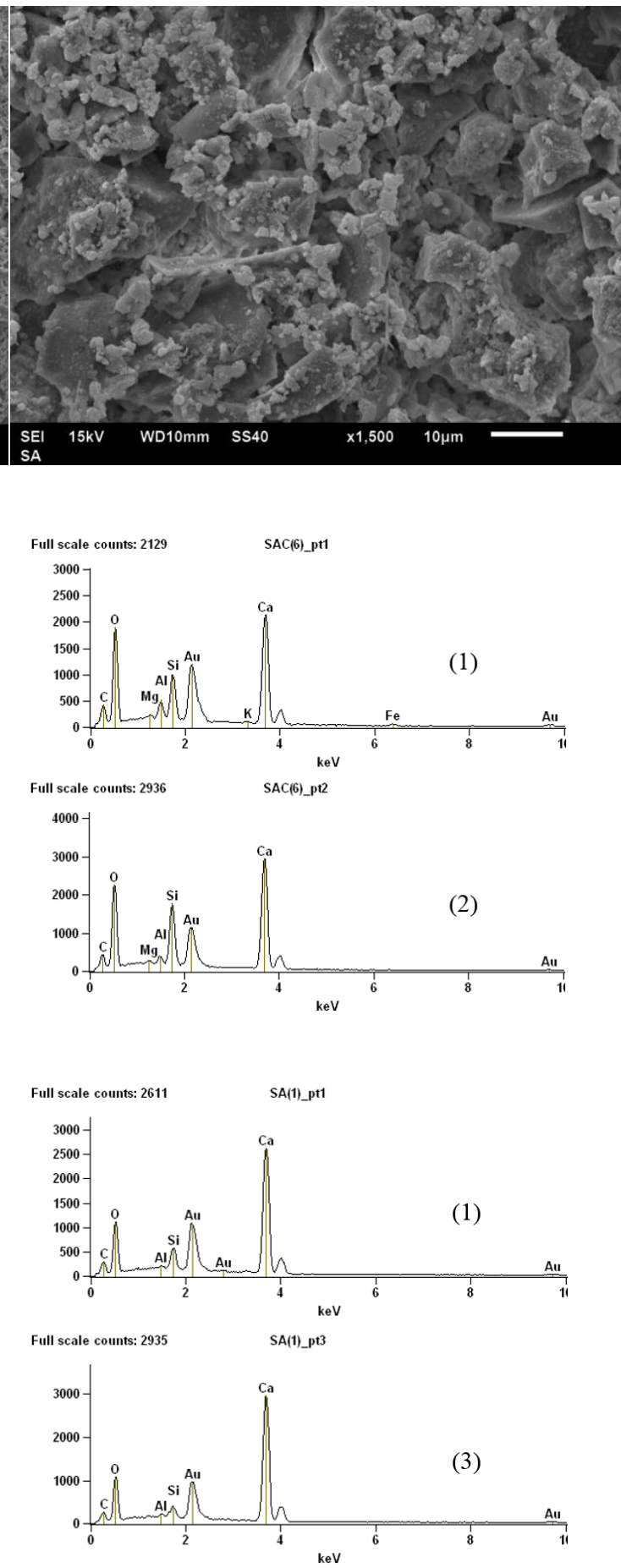
(e)
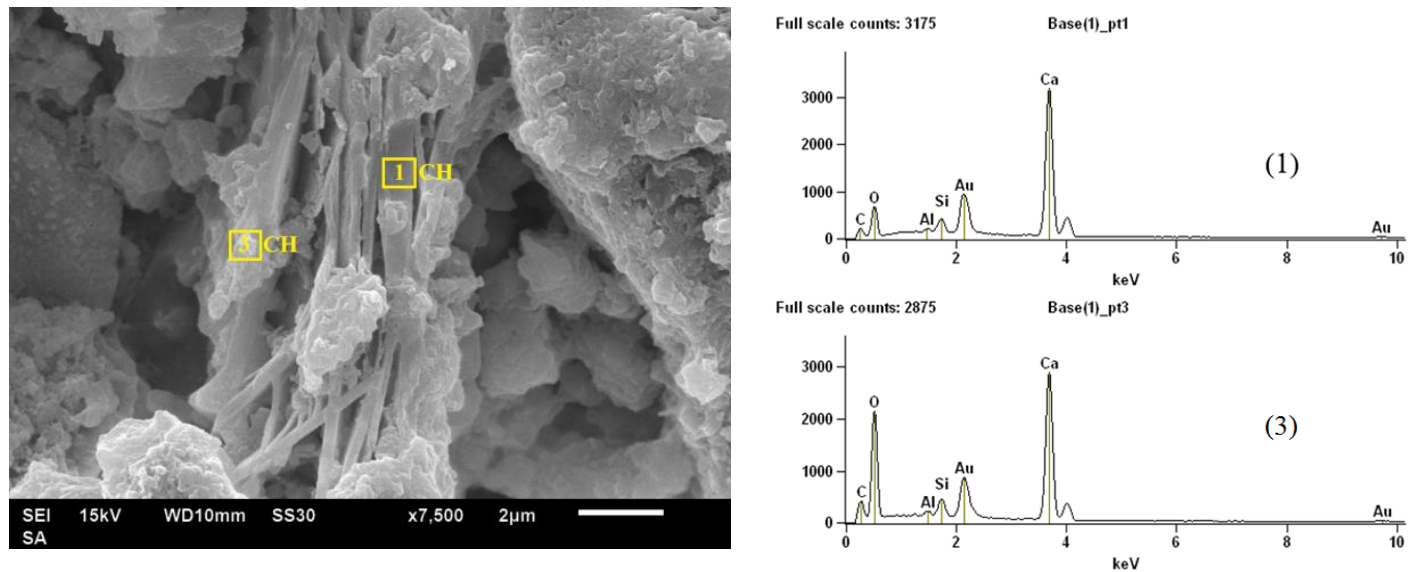

(f)
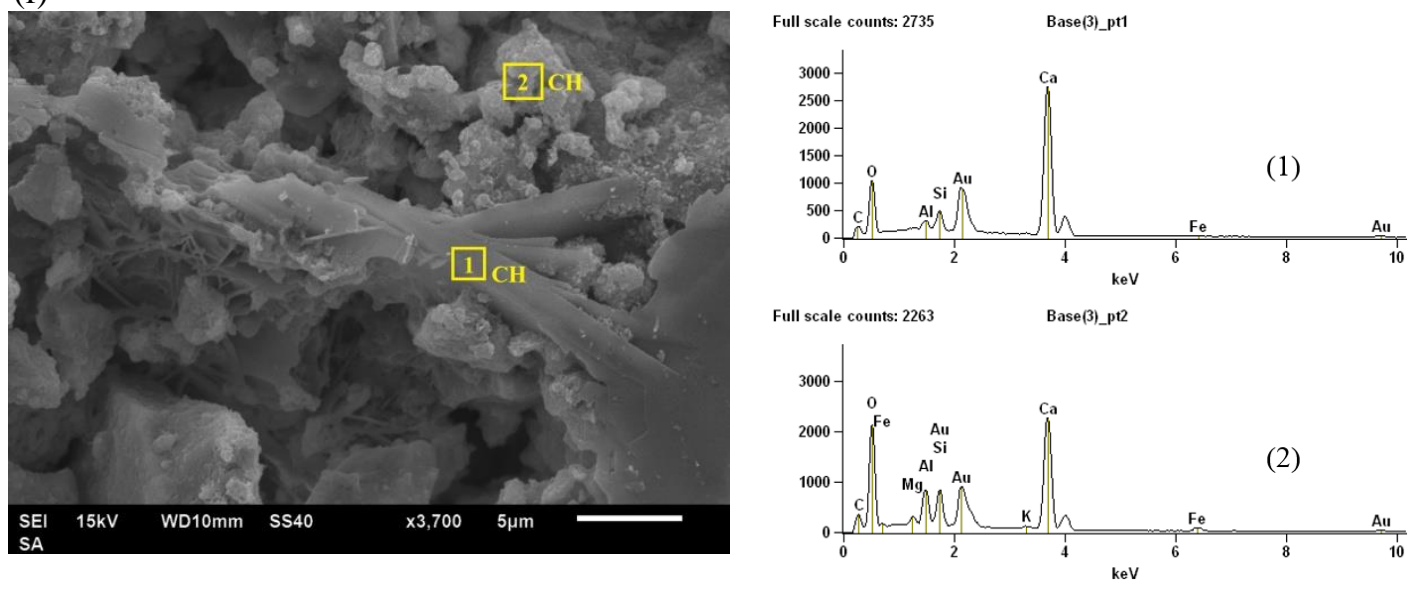

Figura 12: Imagens obtidas via MEV para a pasta constituída de cimento Portland e sílica ativa, acompanhadas dos espectros das microanálises realizadas por EDS.

\section{CONCLUSÕES}

As conclusões do presente trabalho são descritas na sequência:

- O método de preparo das amostras para análise no microscópio de força atômica mostrou-se adequado, pois resolveu o problema da natureza essencialmente rugosa característica das superfícies das pastas cimentícias. Assim, foi possível obter planicidade suficiente para a análise no MFA, o que permitiu a obtenção de imagens nítidas em alta resolução. Após vários testes realizados, recomendase a moldagem das pastas em pequenos moldes retificados (obtidos por corte de tubo de PVC em torneadora de precisão) e sobre placas de mica recém clivadas.

- Com relação ao quadrículo de aproximadamente $3 \mathrm{~mm}$ x $3 \mathrm{~mm}$ demarcado manualmente com pincel marcador sobre as pastas analisadas por MFA, para posterior análise ao MEV (com a realização de microanálises por EDS), verificou-se a impossibilidade de, com este procedimento, ter certeza da região exata varrida pelo microscópio de força atômica, já que diante do alto nível de ampliação exigido por esta técnica, tornou-se excessivamente grande a área manualmente demarcada (de $3 \mathrm{~mm}$ x $3 \mathrm{~mm}$ ).

- Foi possível perceber, nas imagens obtidas por MFA, as diferenças topográficas (de relevo) que caracterizam a as zonas de ligação entre fases hidratas da pasta de cimento. Nesse sentido, ficou clara que a amostra contendo apenas cimento e água resultou em um sistema menos complexo, com menos fases em contato e tendo-se situações nas quais se percebiam placas de $\mathrm{CH}$ orientadas (na interface com o molde de mica). As pastas contendo sílica ativa, embora representem sistemas mais complexos, com mais fases hidratadas ligadas, evidenciaram estruturas mais densas e compactas, condizentes com a ação pozolânica esperada da sílica ativa, que produz C-S-H adicional e consumo de placas de $\mathrm{CH}$. Sobretudo na idade de análise das amostras (28 dias), a complexidade observada 
nas imagens de MFA também pôde expressar sistemas com reações pozolânicas em ocorrência.

- As análises ao MEV ressaltaram aspectos microestruturais que confirmam a maior compacidade da pasta de cimento com sílica ativa. As microanálises por EDS evidenciaram nas zonas delimitadas por pincel (as mesmas que foram varridas na MFA - embora com ampliações diferentes) a presença básica de C-S-H e CH, tanto nas pastas de cimento quanto nas pastas de cimento e sílica ativa, com maior preponderância de C-S-H nesta última (o que corrobora sua maior densificação e compacidade). Não foram identificadas nas áreas de análise a presença de etringita ou de monossulfato.

Como considerações finais, pode-se dizer que a microscopia de força atômica gera resultados complexos e ainda com grande potencial de conhecimento, experiência e aplicação. A utilização da técnica é pouco consolidada para a análise de pastas cimentícias, sendo uma de suas principais restrições a impossibilidade de identificação química das regiões que analisa, bem como a exigência de planicidade e nivelamento superficial das amostras, dada a alta proximidade exigida entre a ponteira do microscópio e a superfície analisada. Contudo, é alta a capacidade que a técnica apresenta de percepção de fenômenos em escalas muito reduzidas e, por isso, é importante que continue a ser utilizada, especialmente em estudos de caráter nanocientífico.

\section{AGRADECIMENTOS}

Os autores agradecem a toda a equipe do Laboratório Multiusuário de Microscopia de Alta Resolução, da Universidade Federal de Goiás - LABMIC/UFG, pelo imprescindível apoio no desenvolvimento deste trabalho. Agradecem também à CAPES pela concessão de uma bolsa de mestrado e ao CNPq - Conselho Nacional de Desenvolvimento Científico e Tecnológico pelas bolsas concedidas aos pesquisadores (PQ).

\section{BIBLIOGRAFIA}

[1] MEHTA, P. K., MONTEIRO, P. J. M., Concreto - microestrutura, propriedades e materiais. 3. ed., São Paulo, IBRACON, 2008.

[2] GLEIZE, P.J. P., "Nanotecnologia e Materiais de Construção", In: Isaia, G.C. (ed.). Materiais de Construção Civil e Princípios de Ciência e Engenharia de Materiais. 2 ed., cap. 53, São Paulo, IBRACON, 2010.

[3] PELISSER, F. Síntese e caracterização de nanocompósitos de silicato de cálcio hidratado-polímeros, Tese de D.Sc., PPGEC/UFSC, Florianópolis, SC, Brasil, 2010

[4] BINNIG, G., QUATE, C. F., GERBER, C. “Atomic Force Microscope”, Physical Review Letters, v. 56, n. 9, pp. 930-933, 1986.

[5] SCRIVENER, K. L., "Nanotechnology and cementitious materials", In: Proceedings of the Nanotechnology in Construction 3 - NICOM 3, pp. 37-42, Prague, Czech Republic, 2009.

[6] PELED, A., CASTRO, J., WEISS, W. J. “Atomic force and lateral force microscopy (AFM and LFM) examinations of cement and cement hydration products", Cement \& Concrete Composites, v. 36 pp. 48-55, 2013.

[7] IBARRA, Y. S., GAITERO, J. J., ERKISIA, E., et al., "Atomic force microscopy and nanoindentation of cement pastes with nanotube dispersions", Applications and materials science, v. 203, n. 6, pp. 1076-1081, may 2006.

[8] JENNINGS, H. M., THOMAS, J. J., GEVRENOV, J. S., et al., “A multi-technique investigation of the nanoporosity of cement paste", Cement and Concrete Research, n. 37, pp.329-336, 2007.

[9] MONDAL, P., SHAH, S. P., MARKS, L. D., "Nanoscale Characterization of Cementitious Materials", ACI Materials Journal, v. 105, n. 2, pp.174-179, 2008.

[10] VANDAMME, M., ULM, F-J., FONOLLOSA, P., "Nanogranular packing of C-S-H at substochiometric conditions", Cement and Concrete Research, v. 40, pp 14-26, 2010.

[11] CHEN, J. J., SORELLI, L., VANDAMME, M., et al., “A coupled nanoindentation/SEM-EDS study on low water/cement ratio Portland cement paste: evidence for C-S-H/Ca(OH $)_{2}$ nanocomposites", Journal of the American Ceramic Society, v. 93, n. 5, pp. 1484-1493, 2010.

[12] SOUZA, L.M.S., Estudo de hidratação e nanoindentação de pastas de cinza da casca de arroz e cinza do bagaço de cana-de-açúcar com hidróxido de cálcio, Dissertação de M.Sc, Programa de Pós-Graduação em Engenharia Civil, COPPE/UFRJ, Rio de Janeiro, RJ, Brasil, 2011.

[13] CBPF - CENTRO BRASILEIRO DE PESQUISAS FÍSICAS. http://www.cbpf.br/ nanos/Apostila/01. html e 04.html. Acessado em 15 de fevereiro de 2012. 
[14] HERRMANN, P. S. P., SILVA, M. A. P., BERNARDES, R., et al., "Microscopia de Varredura por Força: uma ferramenta poderosa no estudo de polímeros", Polímeros: ciência e tecnologia, v. 7, n. 4, pp. 51-61, 1997.

[15] PSI - PARK SCIENTIFIC INSTRUMENTS, A practical guide to scanning probe microscopy, 1996.

[16] ISRAELACHVILI, J. N., Intermolecular and surface force, 2. ed., San Diego, Academic Press, 1992.

[17] DI - DIGITAL INSTRUMENTS, Nano Scope Command Reference Manual, Santa Bárbara, [s.d.].

[18] VANCSO, G. J., SCHÖNHERR, H., Scanning Force Microscopy of Polymers, 1 ed., Springer, 2010.

[19] FROMMER, J. "Scanning probe microscopy of organics - an update", Thin Solids Films, v. 273, n. 1-2, pp. 112-115, 1996.

[20] YANG, T., KELLER, B., MAGYARI, E., “AFM investigation of cement paste in humid air at different relative humidities", Journal of Applied Physics, v. 35, n. 8, pp. L25-L28, 2002.

[21] YANG, T., KELLER, B., MAGYARI, E., HAMETNER, K., et al., "Direct observation of the carbonation process on the surface of calcium hydroxide crystals in hardened cement paste using an Atomic Force Microscope", Journal of Materials Science, v. 38, n. 9, pp. 1909-1916, 2003.

[22] PELED, A., WEISS, J., "Hydrated cement paste constituents observed with Atomic Force and Lateral Force Microscopy", Construction and Building Materials, v. 25, n. 11, pp. 4299-4302, 2011.

[23] NONAT, A., "The structure and stoichiometry of C-S-H”, Cement and Concrete Research, v. 34, n. 9, pp. 1521-1528, 2004.

[24] PELLENQ, R. J-M., VAN DAMME, H., "Why does concrete set? The nature of cohesion forces in hardened cement-based material", MRS Bulletin, pp.319-323, 2004.

[25] FONSECA, P. C., JENNINGS, H. M., ANDRADE, J. E., "A nanoscale numerical model of calcium silicate hydrate", Mechanics of Materials, v. 43, pp. 408-419, 2011. 